\title{
Recursos educacionais na disciplina de estatística
}

Educational resources in the module of statistics

\author{
Maria Helena Rigão', Maria Cristina lop² \\ I Departamento de Estatística- Universidade Federal de Santa Maria- hrigao@yahoo.com.br \\ 2 Universidade de Santa Cruz do Sul-mcriop@gmail.com
}

\section{Resumo}

Este trabalho teve como objetivo promover e ampliar a presença das tecnologias de comunicação e informação na dimensão educacional do ensino de Estatística, a fim de favorecer a integração, interatividade e colaboração entre os envolvidos no processo educativo e formador da Universidade Federal de Santa Maria - UFSM. As disciplinas envolvidas foram: Introdução à Probabilidade e Estatística, Turma 13 e Estatística Aplicada a Qualidade, Turma 10. Como resultado, evidenciou-se que o uso dos recursos de tecnologias da informação e comunicação (TIC), nas atividades educacionais propostas, promoveu a autonomia e fluência tecnológica dos estudantes, bem como a colaboração e interação entre eles. Concluiu-se que a integração entre os recursos de TIC e outros, já tradicionalmente utilizados na disciplina de Estatística, contribuíram como fator de sucesso para a formação dos estudantes.

Palavras Chave: recursos educacionais, estatística, tecnologias da informação e comunicação

\begin{abstract}
This research aimed to promote and expand the presence of information and communication technologies in the educational dimension of Statistics teaching, favoring integration, interactivity and collaboration among those involved in the educational process and trainer UFSM. The subjects involved were: Introduction to Probability and Statistics and Applied Statistics Quality. As a result, it became clear that the use of ICT resources in educational activities proposed, promoted the autonomy and technological fluency of students, as well as collaboration and interaction between them. It was concluded that the integration between ICT and other resources, traditionally used in the discipline of Statistics, as success factor contributed to the training of students
\end{abstract}

Keywords: educational resources, statistics, information and communication technologies 


\section{INTRODUÇÃO}

O processo de ensino-aprendizagem de Estatística nos cursos de graduação representa um grande desafio, tanto para os estudantes quanto para os professores. De acordo com NOLAN e SPEED (1999), os alunos têm dificuldade em aplicar os conceitos estatísticos aprendidos em sala de aula a contextos independentes, tanto no trabalho quanto em problemas reais, ou mesmo em outras disciplinas de seus cursos. Isso ocorre por não conseguirem fazer uma relação entre a utilização da Estatística e situações reais.

Por outro lado, os desafios contemporâneos levam a repensar a educação, oferecendo novas alternativas para os indivíduos interagirem e se expressarem, diversificando as formas de agir e aprender, considerando a cultura e os meios de expressão que a permeiam (MARTINSI, 2008). $\mathrm{O}$ avanço da tecnologia permitiu que o acesso à informação se tornasse muito mais rápido e fácil e, o uso de tecnologias como apoio ao ensino e à aprendizagem vem evoluindo rapidamente e trazem trazendo efetivas contribuições à educação. (ALMEIDA e PRADO, 2009).

Para Coutinho (2009),

Na era da globalização, em que é inquestionável o poder educativo das TICE, mas em que se sabe também que esse potencial depende do modo como professores e alunos as inserem no processo didáctico, parece importante lembrar que a tecnologia só faz sentido se usada com intencionalidade, ou seja, se correctamente integrada na concepção e desenvolvimento de todo um projecto curricular. Urge, pois, que estes dois domínios científicos se dêem as mãos e definam linhas de actuação concertadas e coincidentes (p. 124).

PAN (2003) aponta mudanças na forma de se ensinar Estatística por meio do emprego das diversas mídias. A utilização das tecnologias possui como ponto forte o envolvimento do estudante em seu próprio processo de aprendizagem, gerando automotivação ao estudo. O professor, além de dividir o controle do processo de ensino-aprendizagem com o estudante, presta cuidadosa atenção ao progresso de cada um individualmente.

De acordo com Moran (2000),

mudanças na educação dependem também dos alunos. Alunos curiosos e motivados facilitam enormemente o processo, estimulam as melhores qualidades do professor, tornam-se interlocutores lúcidos e parceiros de caminhada do professor-educador. Alunos motivados aprendem e ensinam, avançam mais, ajudam o professor a ajudá-los melhor (p.17).
Nesse sentido, as ferramentas da educação a distância propõem uma mudança de paradigma educacional à medida que incentivam a aprendizagem colaborativa por meio da interação aluno/ conteúdo, aluno/aluno e aluno/professor on-line (PINHEIRO 2002). A interação é apontada como importante fator no sucesso dos cursos on-line, pois incentiva a discussão, reduz a sensação de isolamento e distância e aumenta o contato do estudante com os professores. Assim, acredita-se que a integração e convergência das tecnologias de comunicação e informação, na disciplina de Estatística, possibilitem a formação de redes de produção colaborativa de conhecimento acadêmico, científico e profissional, desempenhando um importante papel na formação sócio-educacional dos estudantes.

A UFSM, desde 2005, integrou-se ao Sistema Universidade Aberta do Brasil (UAB), em função disso, muito já foi realizado em termos de pesquisa sobre o ambiente virtual de ensino-aprendizagem livre Moodle - Modular Object-Oriented Dynamic Learning Environment. Através do Moodle, é possível produzir conteúdos web hipermídia nas disciplinas no âmbito das tecnologias de informação e comunicação. Além disso, segundo BASTOS et al. (2008), o Moodle potencializa, tanto a interação quanto a interatividade na comunicação mediada por computador.

Dada a flexibilidade do Moodle, como ambiente virtual de ensino aprendizagem e por promover a interatividade dos alunos com os recursos educacionais, justifica-se a pesquisa de recursos educacionais em Estatística, para uso nas disciplinas presenciais, mediadas por esta ferramenta.

Para Mallman e Catapan (2010),

\footnotetext{
performance docente requer assentamento nos princípios da competência (saber fazer), desejo (querer fazer) e autonomia (poder fazer). Esses princípios precisam garantir a elaboração de materiais didáticos que comportem as delegações necessárias ao processo ensino-aprendizagem (p. 371).
}

Assim que esta pesquisa também contribuirá na performance dos docentes envolvidos, pois estes deverão planejar, desenvolver e avaliar estratégias de ensino aprendizagem, além de selecionar quais as tecnologias mais adequadas se aplicarão a esta disciplina.

Este estudo teve como objetivo promover e ampliar a presença das tecnologias de comunicação e informação, na dimensão educacional do ensino de Estatística, com vistas a favorecer a integração, interatividade e colaboração entre os envolvidos 
no processo educativo e formador da UFSM.

\section{METODOLOGIA}

Este trabalho foi desenvolvido no segundo semestre letivo de 2012 com os estudantes das disciplinas Introdução à Probabilidade e Estatística, Turma 13, Curso de Meteorologia e Estatística Aplicada a Qualidade, Turma 10, Curso de Química Industrial, da UFSM, e envolveu 32 alunos. Na primeira semana de aulas, aplicou-se um questionário aos estudantes para identificar as possíveis dificuldades na utilização do Moodle; suas experiências anteriores com essa ferramenta e suas expectativas no processo ensino-aprendizagem da disciplina. No decorrer do semestre, a disciplina desenvolveu-se com as tradicionais atividades de aula, assim como outras atividades colaborativas e interativas, uso do Moodle (glossário, fórum, envio de arquivos de pesquisa) e internet (vídeos e construção de um blog da disciplina). Na última semana de aulas, outro questionário foi aplicado para verificar qual a avaliação feita pelos estudantes do desenvolvimento da disciplina de Estatística através de diferentes recursos educacionais.

\section{RESULTADOS E DISCUSSÃO}

Após a tabulação do questionário aplicado na primeira semana de aulas, identificou-se que todos os estudantes têm computador e possuem acesso à Internet em suas residências. A Internet é utilizada, primeiramente, para conectar a redes sociais (Facebook e outros); depois, para falar com amigos e parentes, usando skype, msn e outros; em terceiro lugar, para enviar e-mails e; por último, para estudo. Conclui-se assim que os estudantes não vêem a Internet como um recurso próprio, possível de ser utilizado para estudo. Apenas 22\% dos pesquisados nunca utilizaram o Moodle. Dos que já utilizaram o Moodle, $52 \%$ disseram ter encontrado dificuldades em seu uso, ou por não terem orientações claras ou por não receberem nenhuma orientação para o uso do ambiente. Em função disso, realizou-se uma aula no laboratório de informática para que os estudantes familiarizarem-se com o Moodle e tirassem suas dúvidas.

No desenvolvimento da disciplina, uma das atividades propostas foi construir e enviar, via Moodle, um texto sobre séries estatística, tabelas e gráficos (Figura 1). As tabelas e gráficos deveriam ser buscadas na Internet. O texto deveria ser redigido dentro das normas da MDT (2012) e as tabelas elaboradas dentro das normas do IBGE (1993). Nessa atividade os estudantes puderam identificar os inúmeros equívocos cometidos, em sites, jornais e revistas, no uso de tabelas e gráficos, compartilhar imagens com colegas, discutir as dúvidas com colegas e professora e utilizar as normas de apresentação de trabalhos da UFSM e as normas do IGBE.

Outra atividade foi a criação de um glos-

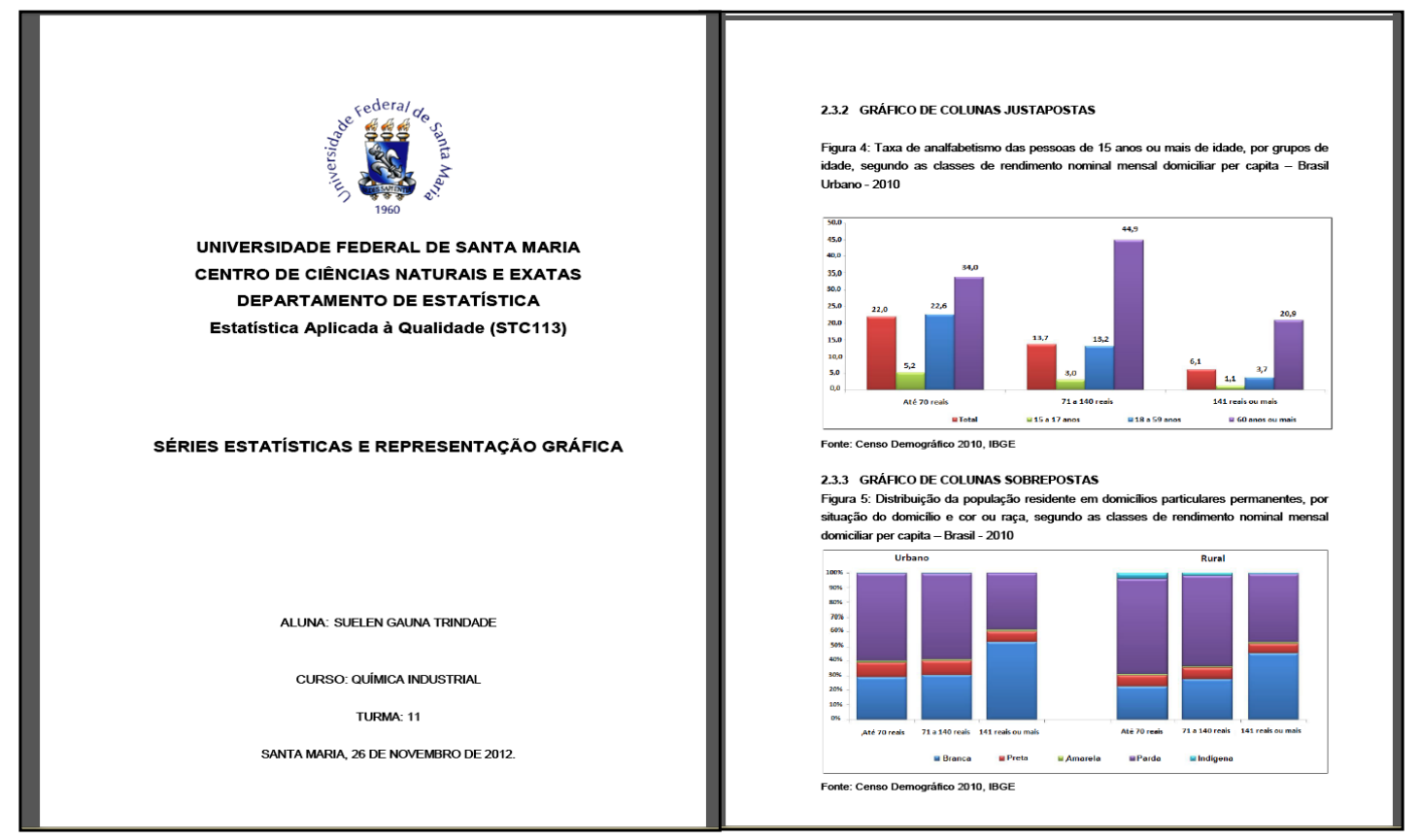

Figura 1 - Recorte de um texto enviado, sobre séries estatísticas tabelas e gráficos. 


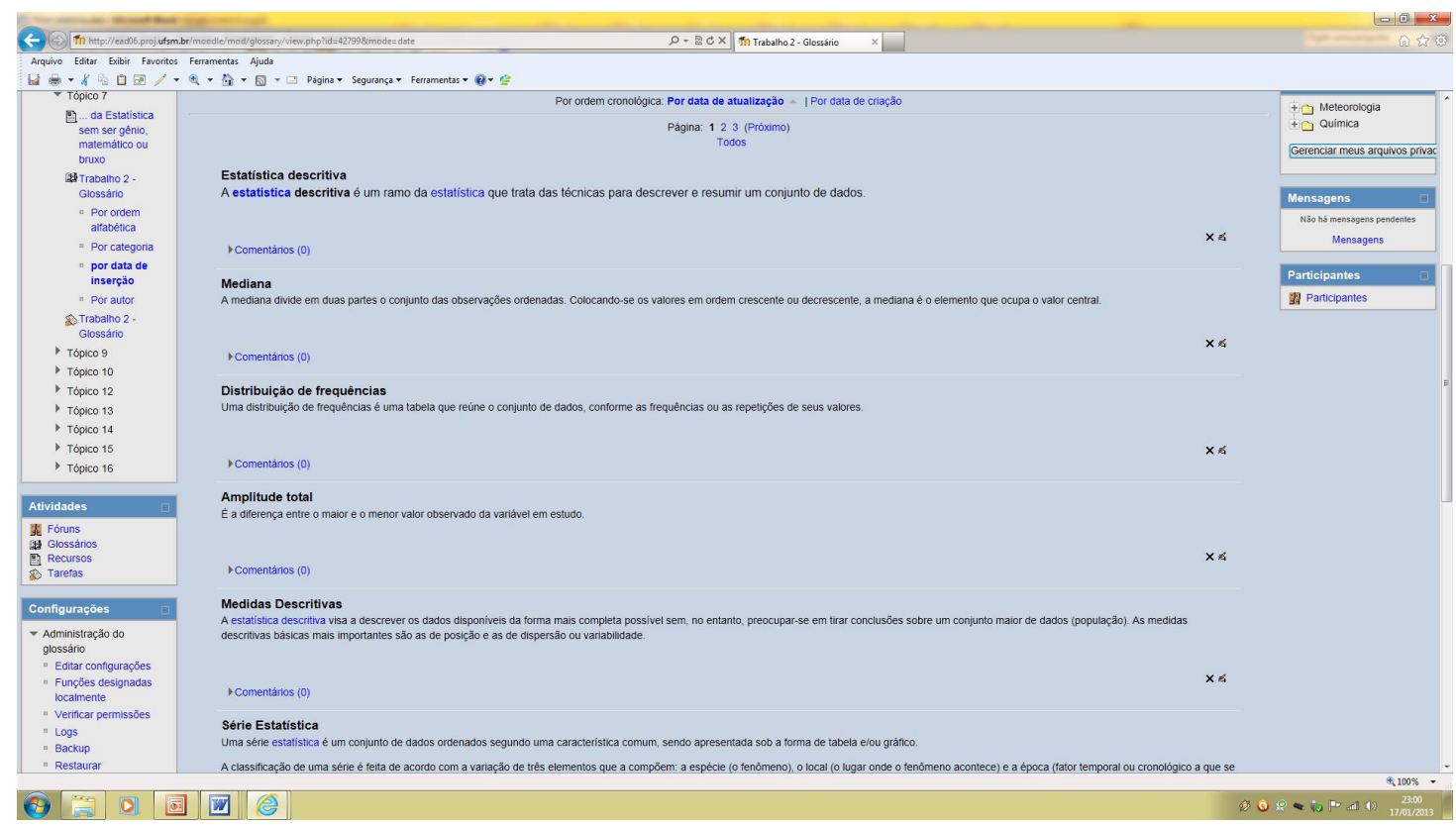

Figura 2 - Recorte do glossário criado no Moodle

sário (Figura 2), no Moodle, dos termos mais utilizados na disciplina. O uso de links permite o rápido acesso as definições, ou significados, de termos citados nos diversos textos em html da disciplina, disponíveis no ambiente Moodle .

Também se realizou a atividade Fórum (Figura 3) onde, depois da leitura do texto: "Entendendo a importância da Estatística sem ser gênio, matemático ou bruxo", de LOPES (2008), pedia-se que os estudantes refletissem e discutissem sobre a importância da Estatística em seu dia a dia e na sua profissão. Embora a participação dos estudantes possa ser considera tímida, na realização desta atividade, suas reflexões foram importantes, mostrando que todos reconhecem a importância da Estatística em sua futura profissão.

Essa atividade veio corroborar a afirmação de MANTOVANI (2009), quando diz que o fórum pode ser efetivamente aplicado ao ensino de Estatística, contribuindo para a aprendizagem,

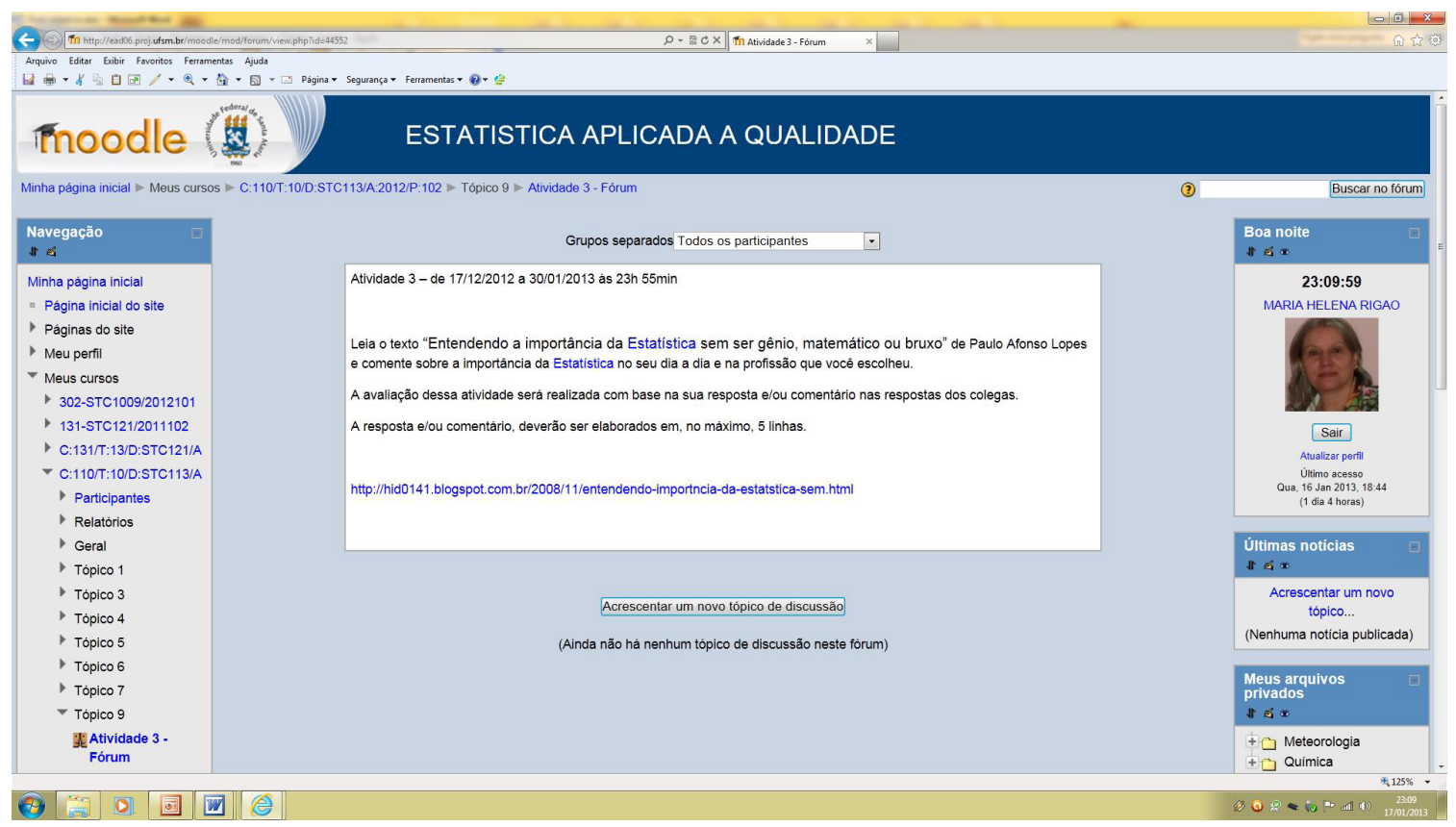

Figura 3 - Recorte da atividade Fórum do Moodle 


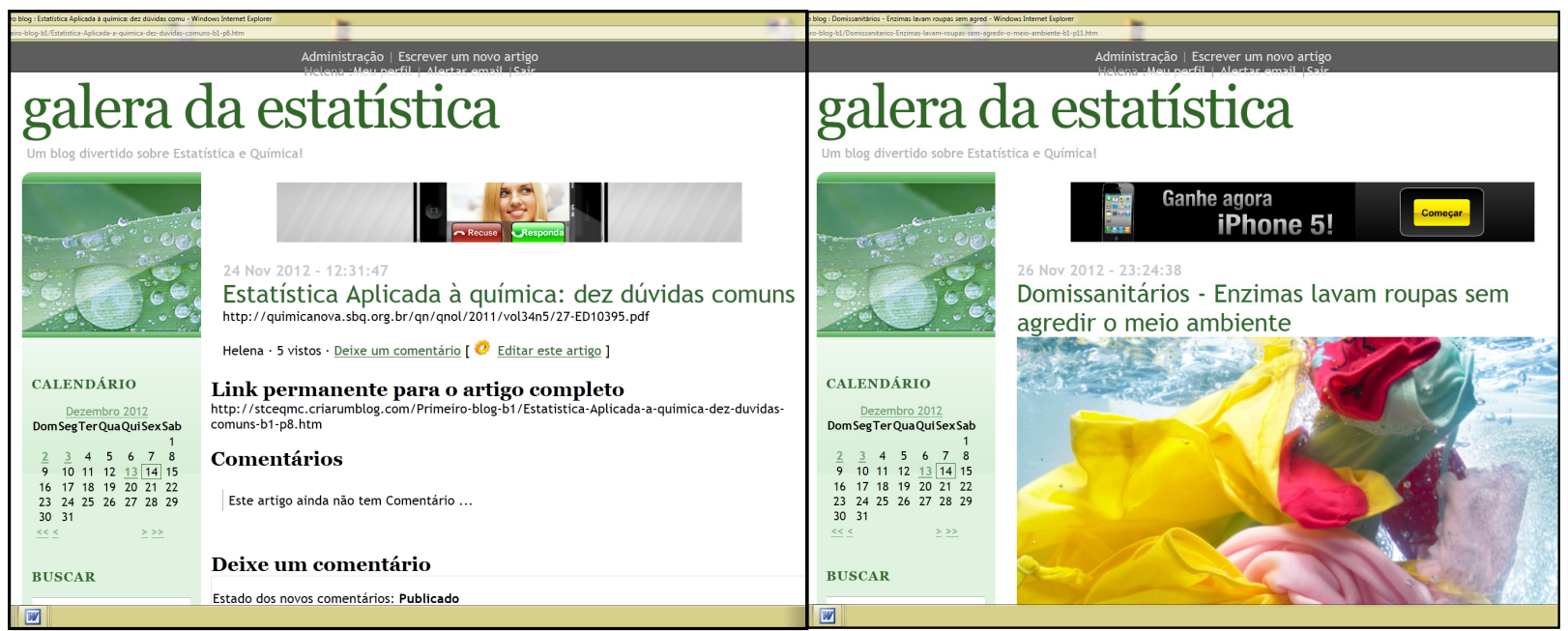

Figura 4 - Recorte do Blog "Galera da Estatística” do Curso de Química Industrial

já que o estudante é incentivado a participar ativamente das discussões, envolvendo-se mais em seu processo de aprendizagem.

Outra atividade proposta foram os blogs, pois segundo MARINHO (2007), os blogs educacionais são ferramentas instrucionais centradas na aprendizagem. Como atividade centrada nos estudantes, os blogs permitem que esses desenvolvam a capacidade de atuar, tanto individualmente, como em grupo, atributos que hoje são reconhecidos como importantes e essenciais para as pessoas na sociedade contemporânea.

Moresco e Behar (2013) dizem que o uso do blog educativo, torna-se um espaço educacio- nal privilegiado, pois permite a reflexão sobre a leitura e a escrita do que é postado pelo autor, bem como sobre as mensagens postadas pelos visitantes, que colaboram e cooperam formando uma comunidade aberta e receptiva. Desta forma, são ampliadas as possibilidades de um diálogo mais autêntico e profundo com outras formas de saber, outros pontos de vista, favorecendo a interdisciplinaridade, ajudando a construir redes sociais e redes de saberes. (p.3)

Para isso foi criado um blog para a disciplina Estatística Aplicada a Qualidade, do Curso de Química Industrial (Figura 4) e outro para a disciplina Introdução à Probabilidade e Estatística do

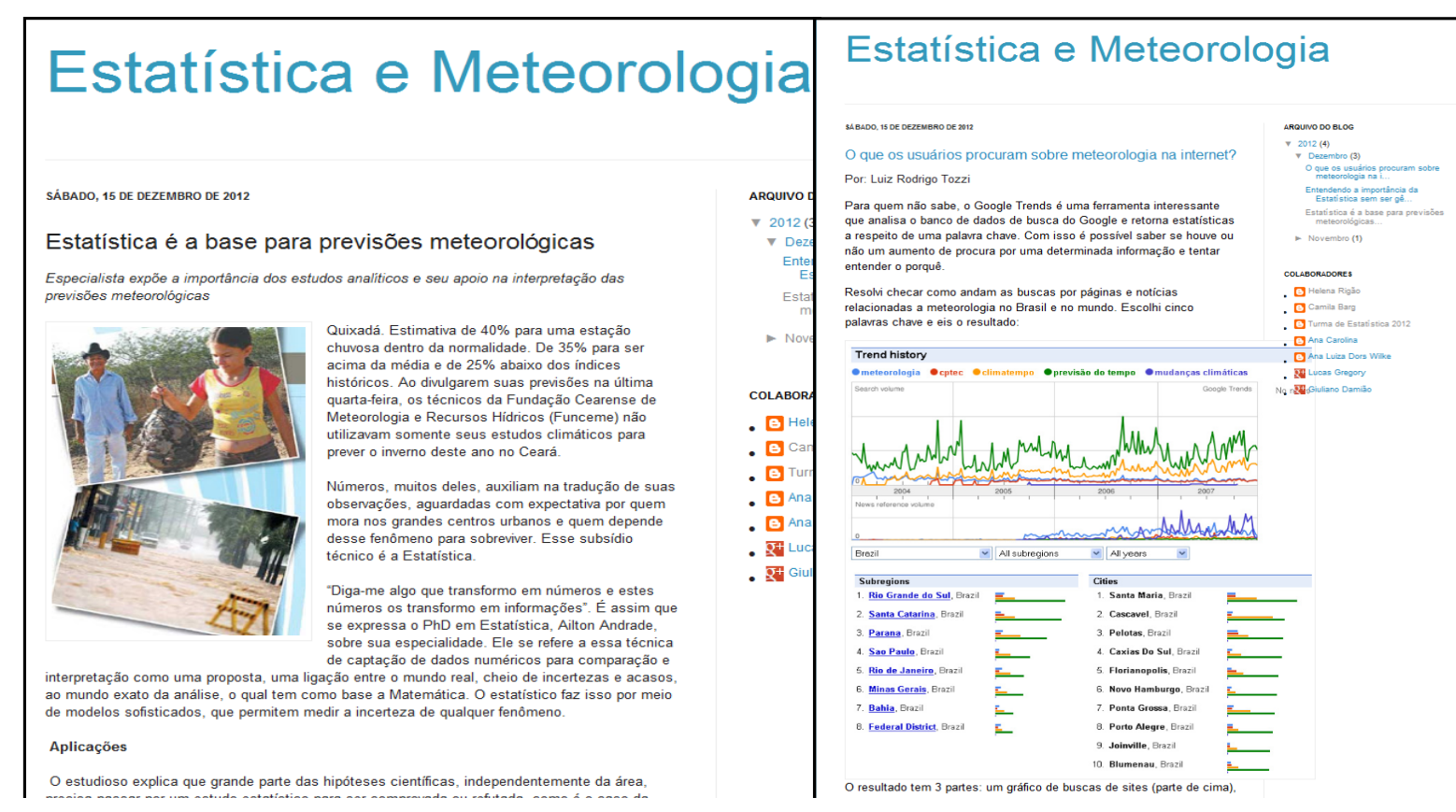

Figura 5 - Recorte do Blog "Estatística e Meteorologia" do Curso de Meteorologia 
Curso de Meteorologia (Figura 5). Todo o processo de construção foi realizado pelos estudantes dessas disciplinas. Eles escolheram o melhor site para hospedar os blogs, o nome, a senha, etc. A professora foi, apenas, mais uma participante, contribuindo com alguns posts. O objetivo dos blogs foi divulgar informações de estatística aplicada aos seus cursos, bem como divulgar inovações nas respectivas áreas de interesse.

O envolvimento dos estudantes na construção dos blogs foi surpreendente. Foi o recurso com maior discussão, participação e integração em sala de aula. Nele, os estudantes publicaram seus materiais de pesquisa e interesse, que, na maioria das vezes, era desconhecido dos outros colegas. Como a disciplina de Estatística é oferecida nos primeiros semestres dos cursos da UFSM e sua aplicação, em outras disciplinas, ocorre nos últimos semestres e no trabalho de conclusão de curso (TCC), os estudantes, às vezes, não percebem sua importância e questionam o porquê da Estatística estar incluída no currículo de seu curso. O blog se mostrou um recurso importante para mostrar a aplicabilidade da Estatística. Estas aplicações não poderiam ser vistas em uma disciplina desenvolvida sem o auxilio de TIC.

A atividade blog reforçou o pensamento de LÉVY (2000), quando diz que um blog pode ser uma estratégia para promover o pensamento crítico e analítico; estimular a criatividade, pensamentointuitivo e associativo; aumentar as possibilidades de acesso à informação de qualidade; combinar o melhor da reflexão solitária e interação social, em um exercício de inteligência coletiva.

Outro recurso, também disponibilizado no Moodle, foram os vídeos informativos e vídeos de revisão de conteúdos como: A História da Estatística; Cálculo de medidas descritivas na calculadora; Noções de probabilidade.

No questionário realizado ao final da disciplina, os estudantes foram unânimes em responder que não tiveram dificuldades em realizar as atividades e enviá-las utilizando o Moodle. Quando perguntado, se preferiam ter entregado a atividade de Tabelas e Gráficos no papel, todos responderam que não, evidenciando, assim, sua aprovação no uso de recursos midiáticos.

A atividade que eles mais gostaram foi o blog e a que menos gostaram foi o fórum. Ao serem questionados sobre a permanência das atividades no Moodle e internet, nas próximas disciplinas, 97\% responderam que elas deveriam permanecer.

Sobre o blog, comentaram que puderam identificar várias aplicações da Estatística em seus cursos, gostaram de conhecer as áreas em que cada colega pesquisa e sugeriram que, nos próximos cursos, seja incentivado o aumento do número de postagens por estudante.

Os resultados deste trabalho pedagógico remetem a importante reflexão:

Ensinar na e com a Internet atinge resultados significativos quando se está integrado em um contexto estrutural de mudança do processo de ensino-aprendizagem, no qual professores e alunos vivenciam formas de comunicação abertas, de participação interpessoal e grupal efetivas. Caso contrário, a Internet será uma tecnologia a mais, que reforçará as formas tradicionais de ensino. A Internet não modifica, sozinha, o processo de ensinar e aprender, mas a atitude básica pessoal e institucional diante da vida, do mundo, de si mesmo e do outro. (MORAN, 1997)

\section{CONCLUSÕES}

Ao termino deste semestre letivo, observando o desempenho e aproveitamento dos estudantes, na realização das atividades propostas e os resultados dos questionários realizados, evidencia-se que o uso dos recursos de TIC, nas atividades educacionais, promoveram a autonomia e fluência tecnológica dos estudantes. Assim como a integração entre os recursos de TIC e outros, já tradicionalmente utilizados na disciplina de Estatística, contribuíram para o desenvolvimento de habilidades e competências dos estudantes das disciplinas Introdução à Probabilidade e Estatística e Estatística Aplicada a Qualidade, favorecendo a integração, interatividade e colaboração destes estudantes e, ao mesmo tempo, promoveram a iniciativa e espírito de equipe, tão desejados hoje no mundo do trabalho.

\section{REFERÊNCIAS BIBLIOGRÁFICAS}

ALMEIDA, M.E.B; PRADO, M.E.B.B. Integração tecnológica, linguagem e representação. 2009. Disponível em: < http://midiasnaeducacao-joanirse.blogspot. com/2009/02/integracao-tecnologica-linguagem-e. html>. Acesso em 22 de abril de 2012.

BASTOS, F. da P. de et al. Exemplares de interação mediada por computador na internet: atividades de estudo e colaboração utilizando a ferramenta wiki no Avea Moodle. In: _. Interação mediada por computador. Santa Maria: Ed. da UFSM; UAB, 2008. p. 25-45.

IBGE. Instituto Brasileiro de Geografia e Estatística. 
Normas de apresentação tabular. 3. ed. Rio de Janeiro. 1993. $62 \mathrm{p}$.

COUTINHO, Clara Pereira. Tecnologia educativa e currículo: Caminhos que se cruzam ou se bifurcam? In: PRADO, Maria Elisabette Brisola Brito; ALMEIDA, Maria Elizabeth Bianconcini de. Elaboração de Projetos:Guia do Cursista. $1^{\text {a }}$ Brasília: Ministério da Educação, Secretaria de Educação a Distância, 2009. p. 124-143.

LÉVY, P. A inteligência coletiva: por uma antropologia do ciberespaço. 3.ed. São Paulo: Loyola, 2000. 212p.

LOPES, P. A. Entendendo a importância da Estatística sem ser gênio, matemático ou bruxo. Blog Licenciatura em História. <http://hid0141.blogspot.com. br/2008/11/entendendo-importncia-da-estatstica-sem. html> . Acesso em 15 de dezembro de 2012.

MALLMANN, E. M.; CATAPAN, A. H. Performance docente na mediação pedagógica em educação a distância. Inter-Ação, Goiânia, v. 35, n. 2, p. 359-372, jul./dez. 2010.

MANTOVANI D. M. N. et al. Educação a distância no ensino de estatística aplicada à administração: uso da ferramenta fórum. Análise, Porto Alegre, v. 20, n. 2, p. 4-19, jul./dez. 2009

MARINHO, Simão Pedro P. Blog na educação \& Manual básico do blogger. Pontifícia Universidade Católica de Minas Gerais, Instituto de Ciências Humanas. 2007. Disponível em: <http://www.scribd.com/doc/2214260/ Blog-na-educacao>. Acesso em 15 de janeiro de 2013.

MARTINSI. M.C. Situando o uso da mídia em contextos educacionais. 2008. Disponível em: <http:// midiasnaeducacao-joanirse.blogspot.com/2008/12/ situando-o-uso-da-mdia-em-contextos.html > . Acesso em 22 de abril de 2012

MDT. Estrutura e apresentação de monografias, dissertações e teses. Universidade Federal de Santa Maria, Pró-Reitoria de Pós-Graduação e Pesquisa, Biblioteca Central, Editora da UFSM. 7. ed. Santa Maria : Editora UFSM, 2012. $72 \mathrm{p}$.

MORAN, J. M. Como utilizar a Internet na educação. Ciência da informação, v. 26, n. 2, p. 146-153, 1997.

MORAN, J.M, Ensino e aprendizagem inovadores com tecnologia, São Paulo, SP: Editora Paulinas, 2000.
MORESCO, Silvia F. S.; BEHAR, Patricia Alejandra. Blogs para a aprendizagem de Física e Química. Disponível em: <http://seer.ufrgs.br/renote/article/ viewFile/14121/7996>. Acesso em: 10 maio 2013.

NOLAN, D.; SPEED, T. P. Teaching statistics theory through applications. The American Statistician, Alexandria, v. 53, 4, p. 370-375, 1999.

PAN, W.S. The challenges of teaching statistics in the current techonology environment. Journal of American Academy of Business, Cambridge, v. 3, p. 351-355, 2003.

PINHEIRO, M. A. Estratégias para o design instrucional de cursos pela internet: um estudo de caso. 2002. 82 f. Dissertação (Mestrado em Engenharia de Produção) - Programa de Pós-graduação em Engenharia de Produção, Universidade Federal de Santa Catarina, Florianópolis, 2002. <http://teses.eps.ufsc.br/tese.asp>. Acesso em 22 de abril de 2012. 